\title{
The Implementation Model of Character Building in Curriculum 2013 Through The Scout Movement as A Required Extracurricular in Primary And Secondary Education
}

\author{
Lena Nuryanti ${ }^{1}$, Deni Darmawan ${ }^{*}, 2$, Achmad Hufad ${ }^{3}$ \\ ${ }^{1}$ Economic Education Department, Indonesia University of Education, 40154, Indonesia \\ ${ }^{2}$ Educational Technology Department, Indonesia University of Education, 40154, Indonesia \\ ${ }^{3}$ Community Education Science Department, Indonesia University of Education, 40154, Indonesia
}

A R T I C L E I N F O

Article history:

Received: 04 November, 2019

Accepted: 20 January, 2020

Online: 07 February, 2020

Keywords:

Personality

Character Education

The Scout

\begin{abstract}
A B S T R A C T
The character education program conducted through extracurricular areas of the Scout. The method used in this study is the Research and Development (R\&D). The research objectives are scouts elementary and junior high school. This research resulted in 3 Prototype Free Model implementation of character education through extracurricular scouting programs in the form of three models that must be followed. All three models include 1) a regular model so-called Block model; 2) Actualization models and 3) Regular models. Having tested through descriptive statistics, the percentage of respondents who obtained the opinion states that the model most widely used is the Block model, which reached 33.78\%. The actualization model application reached $6.75 \%$, while the Regular model application reaches $17.57 \%$. The findings further analysis of the model character education through extracurricular activities scouting in basic education in West Java can be done via the Blocks model. The Results of the obtained tendencies that cause suboptimal extracurricular of the Scout to embed the characters early on elementary and secondary school.
\end{abstract}

\section{Introduction}

The Preamble of the Constitution of the Republic of Indonesia Year 1945 mandates the Pancasila as the nation and Worldview of Indonesia which should animate all areas of development. One of the very important national development and became the foundation of society, nation, and state is the nation's character building [1].

Paying attention to the circumstances of a national character which tend to be chaos and the poor. The government took the initiative to prioritize the development of national character is supposed to be the mainstream of national development. The national character building means that any development effort should always be considered linkages and their impact on the development of character. The national character building reflected in the mission of national development that positions the character education as a mission the first in line for the purpose of the curriculum in 2013. That is to prepare human Indonesia to have the ability to live as individuals and productive citizens, creative,

\footnotetext{
*Deni Darmawan, Email: deni_darmawan@upi.edu
}

innovative, and effective, and be able to contribute to the life society, nation, state, and civilization [2].

Minister of Education and Culture explained that the government will make a whole triangle education activity, namely curricular, extracurricular, and co-curricular. "What we create in the curriculum 2013 [3] is a complete triangle, namely knowledge, skills, and attitudes". Build an attitude could not be done only in the classroom, but it formed through extracurricular and cocurricular activities. For this reason, Scout is one of the required activities in extracurricular. Scout movement teaches the value of leadership, togetherness, and has become a phenomenon not only in Indonesia but also in the world. In harmony with the objectives of the Scout is to form each Scout as follows: 1 have a personality who believe, fear Allah, noble, spirited patriotic, law-abiding, disciplined, upholding the noble values of the nation, competent in life, bodily health, and spiritual; 2 be a citizen of the spirit of Pancasila, faithful and obedient to the unitary of Republic of Indonesia as well as a member of the public good and useful, to establish itself independently as well as jointly responsible for the development of the nation and the state, have concern for others 
life and the natural environment.

Development of a national character building that pursued by a variety of forms, until now has not done optimally. It reflected in socio-economic disparities; political is still great in corruption, and injustice law, pornography, promiscuity, sexual abuse by teenagers committed to minors, violence, and unrest are likely to become more widespread in many sectors. As a result of the unconformity of stakeholders in all sectors of public life currently prevalent such as anarchy, social conflicts, the narrative of bad language and manners, as well as the disobedience of traffic [4].

Indonesian society is accustomed to polite in behavior, implement consensus in resolving the problem, have the local knowledge-rich plurality, and being tolerant and cooperation is now likely to turn into homogeneous groups to outdo each other and behave dishonestly. All of it was confirmed that the uncertainties identity and character of the nation that leads to 1 disorientation and not understand the values of Pancasila as the philosophy and ideology of the nation, 2 the limitations of the policy tools integrated in realizing the values of Pancasila, 3 a shift ethical values in the life of the nation, 4 the waning awareness of the cultural values of the nation, 5 the threat of disintegration and 6 the weakening of the nation's independence.

Therefore, in this study want to answer about: "How the implementation of extracurricular education of the scouts as required in primary and secondary education unit listed in curriculum 2013 and the ministry rule No. 81A [3] which further clarified in ministry rule No. 63 of 2014 [5] of Indonesian government on the implementation of compulsory education extracurricular the Scout?"

The desire to do this research came from the discourse will launch Curriculum 2013 [3] at approximately the end of 2012 until approximately the beginning of 2013 which did not escape the turmoil opinion of the pros and cons of teachers, lecturers and education practitioners, especially in the realm of scouting. May 17,2013 , researchers concluded that the results of the meeting to realize that essentially runs the Act No. 12 of 2010 about the scout movement and understand the rules of education and culture minister No. 81A [5]. Therefore, we consider it is necessary to perform research based on the implementation of the curriculum in 2013 [3], especially concerning the compulsory extracurricular of the Scouts.

This research is expected to contribute to national scouts in an effort to undertake the minister of education and culture to implement the $2013^{\text {th }}$ curriculum. This is, of course, the one side is a gift that the Scouts received praise and trust. However, on the other hand, it is a reminder that all components of the Scouts should prepare to deal with it wisely. Considering that the implementation of the exercise scouts does in the "Gugus Depan" education units ranging from elementary to groups of "Siaga" and "Penggalang," "SMP" for groups of "Penggalang," a high school for "Penegak" until College for "Pandega." Besides, by the basic principles of scouting embracing the principles of voluntarism, air-shift system, the system of separate units, the system marks the skill and honor code of cropping systems as well as outdoor activities. It is the hallmark, and which is the identity of scouting education.

Therefore, it is important to note that the research team had to observe accurately the formulations and wiser response to the two sides that are considered controversy, i.e. their given
"Extracurricular Mandatory" versus "Voluntary Principles" to be a member of the Scouts. The member of the Scouts must be based on the voluntary principles and the word or phrase "love and willingly "this has always been a concomitant sentence pledge or promise dialogue participants before the coach when sworn or affirmed as a member of a variety of requirements.

Outcomes of the research are expected to show a prototype either manual or reference shape model of character education through Scouting as an extracurricular compulsory education that has been tested. This is expected to provide at least a minimum contribution of reference for national education units and education units as a forwarding scout group basis. In the channel used is the path began the National Kwartir, Regional Kwartir, Branches Kwartir, Twigs Kwartir, and Gugus Depan because the next group is spearheading the efforts to establish the character of their students to schools throughout Indonesia.

The position of the regional kwartir of the Scouts movement in West Java in the activities of this study is used as a group control of information. In connection with the Institution of Universitas Pendidikan Indonesia (UPI), wherein Chief Researcher and study members were lecturers of UPI included Cluster front of existing and based in UPI be under the coordination of regional kwartir of west java [6].

\section{Curriculum Development in 2013}

Today the growing demands for changes in the education curriculum emphasize the need to build national character. It based on the facts and perceptions about the declining quality of the attitudes and morals of children or young people. Curriculum 2013 [3] is prepared to print a generation to be ready in facing the future because the curriculum is structured to anticipate future developments. The development of a national character must be actualized substantially in the form of national action to establish the spiritual, moral, and ethical.

This performed through a systematic and integrative approach with the involvement of the family, education units, government, people including peers, young people, the elderly, the mass media, the Scouts, community organizations, political organizations, professional organizations, non-governmental organizations, strategic groups such as structural elite, the political elite, journalists, cultural, religious leaders, traditional leaders, and community leaders.

As for character development strategy, it can be done through awareness, education, empowerment, acculturation, and cooperation with due regard to environmental conditions and community needs as well as a multidisciplinary approach that does not emphasize indoctrination. As mandated by Law 20 of 2003 [7] on National Education Systems in the explanation of Article 35, where the competence of graduates is qualified to graduate capabilities that include attitude, knowledge, and skills by the national standards that have been agreed. Moreover, in the curriculum included, the Scout is compulsory in every school. Scout through the Homeland will be maintained intact.

Curriculum development that occurred in Indonesia is already happened several times, wherewith the curriculum in 2013 [3] is already five times. For more details of how the development of the curriculum of every turn, the shape change of the curriculum that occurred in Indonesia specified in the curriculum of public test material 2013. Triangle Whole Curriculum 2013 [3] to a 
target the new philosophy that proclaimed Indonesian education as an integral part of the learning process of children. The education ministry of Indonesia said that the form of the whole triangle is curricular, co-curricular and extra-curricular. Curricular activity is an activity that must be followed by learners and binding. The curricular program contains a wide range of fundamental skills and abilities students need to have a minimum at level schools (educational institutions).

Co-curricular activities are an integral part of teaching and learning (curriculum) which serves as a support and enrichment curriculum for life skills coaching implemented gradually and continuously. The extracurricular program is an internal part of the learning process that emphasizes meeting the needs of learners. Between curricular and extra-curricular activities cannot be separated, even extra-curricular activities complementary extension or reinforcement curricular activities to channel the talent or driving the development of potential learners to achieve the maximum level. The Scout movement is an integral part of the educational process to prepare to practice a code of honor Scout: "Satyaku ku dharmakan" (my promise is my behave), "Dharma ku kubaktikan" (I actualize my behave). The code is to instill the confidence, adding to the spirit of service to the nation and state, the practice of the Scout's Tri Satya and Dasa Dharma has a work culture that based on devotion to the noble and sincere. Thus, the intact triangle of the curriculum in 2013 [3] will be homework for teachers who spearhead education.

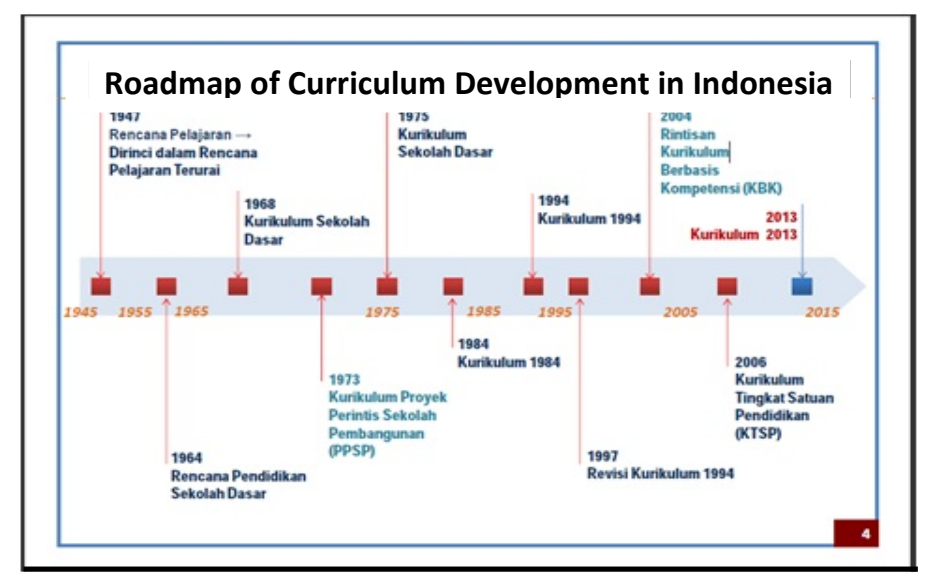

Figure 1: The development of the curriculum in Indonesia [8]

This is presumably as a counterweight formal learning activity in the curriculum which more oriented to the cognitive (knowledge) and psychomotor (skills). The Scouts will be able to build the intelligence of the students in the realm of affection (attitudes and behaviors) so that students will be able to develop a positive character.

\section{Meaning of the Character Building}

Character means behavior or personality. Hill T.A [9] says that "Character determines someone's private thoughts and someone's action done. Good character is the inward motivation to do what is right, according to the highest standard of behavior in every situation".

In this context, the characters can be interpreted as someone's identity. According to Ekowarni [10] on the order of micro, the character is defined as (a) the quality and quantity of the reaction against oneself, another person, or a particular situation; or (b) the character, character, psychological traits. Psychological characteristics of the individual in the private sphere, in evolution will develop into characteristic groups and, more broadly characterize the social. Individual psychological characteristics will give color and patterns of group identity and in the framework of the macro will be a psychological trait or character of a nation.

Based on the above understanding can be said that the character is an identity, personality, and character are inherent in a person. Characters are always related to the physical and psychological dimensions of the individual. The character is the value of the basic behavior of the reference values human interaction (when the character lost then everything lost).

\section{Definition of Education Extracurricular}

About Permendikbud No.81a later confirmed in more specific in Permendikbud No. 63 of 2014, about the implementation of Extracurricular Mandatory Scouting, it is important to know what the sense of Education Extracurricular as follows [3]. Education Extracurricular is "educational activities undertaken by students out of hours learning the standard curriculum as an extension of curriculum activities and carried out under the guidance of the school with the aim of developing personality, talents, interests, and abilities of learners wider or outside interests developed by the curriculum" [11].

The function of the extracurricular the Scout activities includes (1) The function of the development, which supports personal development through the expansion of interests, development potential, and providing opportunities for character formation and leadership training. (2) The social function, namely to develop the ability and internalization of moral and social values, (3) Function recreational, which is carried out in an atmosphere of relaxed, happy, and fun, (4) Function career preparation, namely to develop career readiness of learners through capacity building.

\section{Research Method}

This study uses a quantitative research and development approach (Research and Development). In the opinion of Gall et.al (1996) [12], the research has three main steps, namely: a preliminary study, stage of development, and testing phase. In education, the $\mathrm{R} \& \mathrm{D}$ process has been used in educational research related to educational practice and has published some research findings into educational products that are applicable for the purpose of improvement of learning in the school environment. Process R \& $\mathrm{D}$ has been used to test the predictions and to develop effective instructional interventions that have been used to improve practice in the classroom. As suggested by Gall et.al (1996) [12], the original ten-step R \& D process that has been embraced by the industry, while for research in the field of education has been limited to seven first steps.

Researchers, in this case, will be followed closely in the years to one with a seven-step process of testing, evaluation, and improvement as it has produced valid product research (See Figure 2). R\&D Process “...consists of a cycle in which a version of the product that developed, field-tested, and revised by field test data". explained that the R\&D consists of a cycle of "product was 
developed, field-tested, and revised based on the test data field and has produced educational products are fully ready for operational use in schools."

Step one to seven R\&D processes are includes: (1) the analysis of the research and proof of concept, (2) the product planning and design, (3) product development, (4) field test early, (5) the revision of the prototype, (6) major field test, and (7) the revision of the final product (Borg \& Gall, 1996 pp. 784-785). [12] Figure 1 graphically described the process for this study.

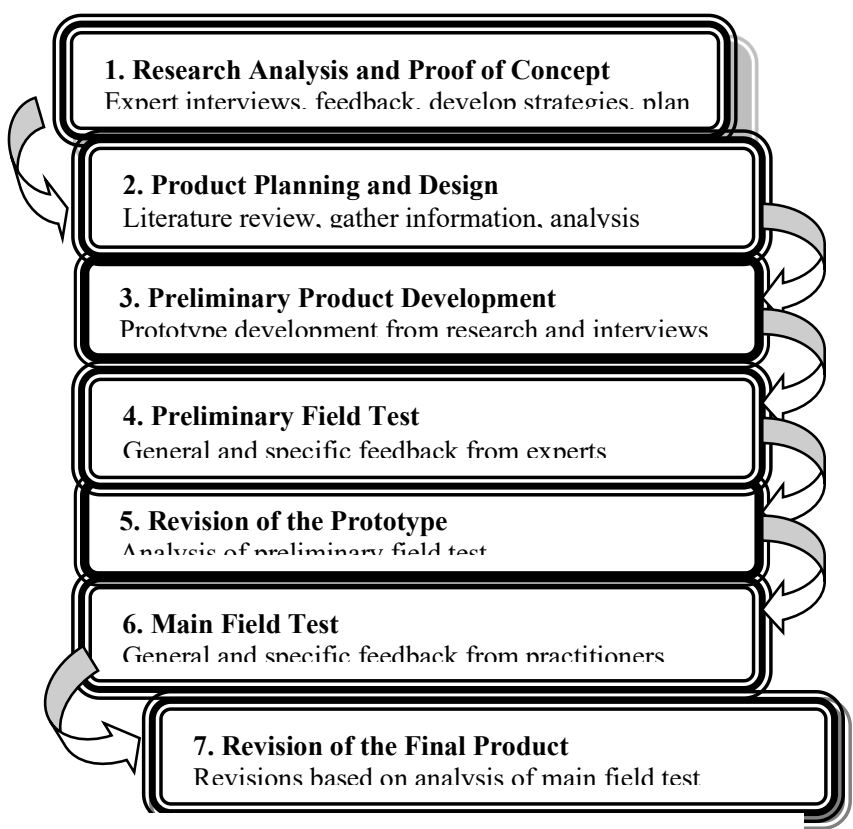

Figure 2: Research Product (Borg \& Gall, 1996 hal. 784-785) [12]

\section{Data Collection Techniques}

The collection of data that researchers use to collect information and data required by the technique as follows:

1) Study Library, which is a technique of data collection is done by collecting, reading, and studying a variety of literature and reading materials related to the problem being studied.

2) Field Studies, namely the collection of data obtained directly, through the following activities:

a. Interviews, namely data gathering activities were carried out to gather information and data with a list of questions prepared in advance in which the questions are asked of informants.

b. Focus Group Discussion (FGD), the activities carried out in the form of a meeting organized by the researchers by inviting competent parties (stakeholders) or the Regional Kwartir and ranks mainstay and coaches scoutmaster required in the study.

3) The collection of additional data and the formulation of the early stages of design through activities Seminar and Workshop.

\section{Processing and Data Analysis}

To undertake the processing and analysis of data obtained from qualitative research, Sugiyono [13] states:

\section{Data analysis is the process of systematically searching and} arranging the interview transcript, field notes, and other

materials that you accumulate to increase your understanding of them and to enable you to present what you have discovered to others.

The opinion makes clear that the activities of data analysis are a systematic process of searching for and compiling the results of interviews, notes, and other resource materials are combined so easily understood and what is gained can be presented to others. Thus, it can be understood that the processing and data analysis is the process of searching and compiling the data obtained as a result of observations, such as notes or interviews. They are arranged systematically by choosing what's important and what is to be learned so that they can be made a conclusion that can be understood by researchers themselves or others. In this study, data will be collected from some respondents. A grating instrument is created to collect data on variations of the model design prototype design for the implementation guide of the extracurricular scouting.

\section{Results and Discussion}

Here are the findings regarding the implementation of the Scout as an extracurricular education compulsory at Primary and Secondary Education unit listed in Curriculum 2013 and in Ministry of Education Rule No. 81A which is further clarified in Ministry of Education Rule No. 63 of 2014 on the implementation of Compulsory Education Extracurricular of the Scout.[3] At the level of schooling, the implementation began in the following stages:

\subsection{Analysis of the implementation level extracurricular of the Scout}

Based on the findings in the field most of the effort to analyze the importance of the Scout in the cluster (gugus depan) level is quite high. These findings are characterized by the number of respondents who stated that The Scout is compulsory in school extracurricular. Various preparations have been done in order to expedite the extracurricular activities, particularly the development of the capacity of a manager or instructor also suggestions infrastructure to support the scouting activities. The Scout extracurricular programs can be followed by all students, either normal students (physically) or those who have disabilities or mental disorders. So, all students have the opportunity to follow the Scout extracurricular program, where all students are equal and there are no differences. In findings regarding equal rights for students to join the program supports the idea of the results of research that has been done by Hong-Joong Cho, Jung-Ran Kim, and Sang-Gu Kim (2015) [14] which states that "Considering our educational climate that difference easily return to superiority or inferiority in our society, two cases of freedom of speech and discriminatory speech in Japan have great implications for us.

\subsection{Legal formal school level in implementing the compulsory education of the Scout extracurricular.}

Based on the research results show that the organizing extracurricular of the Scout at the school level requires decree on mandatory legal standing as for whether or not they are carried. 
The research findings indicate that most respondents from the school state that the decree is important. A decree or legal standing has been owned by the schools in Indonesia, thereby the Scout extracurricular activities are mandatory for all students. To meet the liability aspect of this that the schools should be able to perform as well as possible. This model is a model that is the most beneficial aspect of effectiveness in applying the values of independence, chivalry, honesty, and cultivation of the soul "progressive persist". From this model, the implementation of infrastructure support has been prepared by the schools with adequate facilities and infrastructure. During the implementation of scouting activities then the condition of moral, spiritual must be balanced with the support of the material and financial aspects were adequate. During the execution of an Extracurricular scouting program, the direct leadership of the principal as to be able to control it well, given good leadership at the school level and even universities will be required to oversee all activities until successful. This finding is consistent with the results of previous research conducted by $\mathrm{M}$. Alsharari Mufadhi Ratyan and A. Almadani Maen Moh (2015) [15] which states that "Deans are controlling a work for teaching and scientific research in colleges, leaving all faculty members them with less time in serving the community. And enhancing social responsibilities approaches.

\subsection{Development of Systems and Structures Extracurricular of the Scout}

After the implementation goes well, then the coaching process performed by the scoutmaster at each school. Most of the coaching process has become an important note. Support for extracurricular coaches is done in the form of facility fees, awards, duties, and responsibilities, as well as the cumulative value of the ranks in his career as the coach. To supervise the coaches are often accompanied by parents during the execution of certain activities. Meanwhile, to obtain legal professionals in the field of scouting is then formed kwartir branches at the district level, this is done through the process of coaching kwartir Trustees candidate school level and also formed a team of policy dissemination extracurricular scouting. While at the district level branches formed kwartir that work to training, socialization process of the formation of formators for kwartir and school level.

Basically, the development of learning systems can support the planting of noble values taught in the Scouting extracurricular activities, such as can be done with the e-learning system. Through e-learning is the process of coaching can be done anywhere and anytime, it supports the findings of research carried out by V. Murugananthan and B. L. ShivaKumar, (2015) [16] elearning methodology includes Multimedia learning, technology enhancement, computer-based instruction, computer-based training, computer-aided instruction, web-based learning, and virtual learning. Through these kinds of systems that learning the scouting extracurricular activities could be more widespread and freely followed by all students anywhere and anytime.

\subsection{The Model of the Implementation and Evaluation to the Extracurricular at School}

The implementation process extracurricular education compulsory in every school scouting majority combined model block, actualization, and regular). Given these three models is quite helpful in monitoring the implementation of compulsory education extracurricular scouting done directly or indirectly. To evaluate the process of implementation of compulsory education extracurricular scouting implemented through reporting by the builder school level. All three models support the implementation of all the policies formulated in the General Assembly's decision of the Scout Movement of Indonesia (Keputusan Munas Gerakan Pramuka Indonesia) [17].

During the implementation of extracurricular of the scout programs in schools, they are supporting and which have an impact on the success of this program. Figure. 3 is an overview of the number of supporters and obstacles experienced by schools in Indonesia.

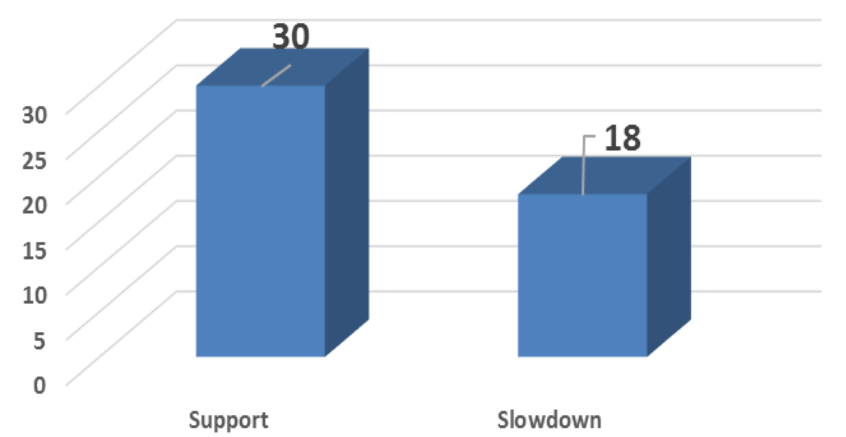

Figure 3: The Scout Implementation at School

\subsection{Implementation of Government Regulation No. 63 Year 2014 [18] concerning Extracurricular of the Scout in Schools.}

The implementation of Law No. 63 of 2014 [18] on the implementation of scouting in school extracurricular otherwise required by approximately 39 schools from 40 school respondents, while 34 schools agreed to continue to apply. In addition, 38 schools out of 40 schools expressed quite relevant and there are 30 schools expressed sufficient support to the success of this program. Figure. 3 is an overview of the results of this study.

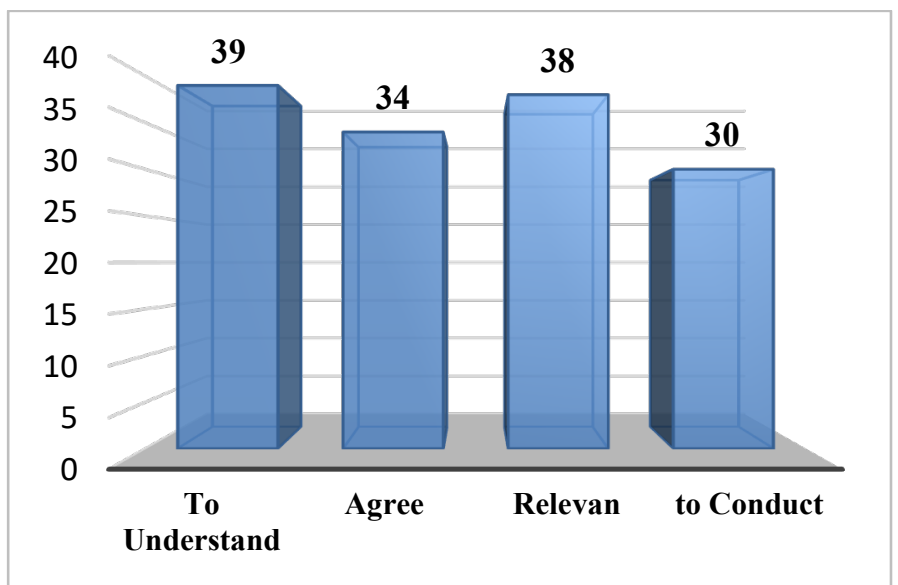

Figure 4: Overview of Implementation the Scout Program based on Government Regulation No. 63 Year 2014 [18]

Successful implementation of the Scout extracurricular program has been basically set in Kwartir Nasional (National Quarter) decision $^{13}$, where each Scout institution organizes the program is obliged to provide support facilities, infrastructure, human resources, as well as adequate financing. The findings of this 
study indicate that the aspect of comprehension, expression agree, relevance and support school institutions is very good. Actual implementation instructions scouting program has been set out clearly by the national quarter of the Scout movement [19].

\section{Measurement of Opinion Successful Implementation of Law No. 64 Year 2014 [18] concerning Extracurricular School.}

Here is the condition of the successful implementation of Law No. 63 Year 2014 [15] regarding the implementation of extracurricular scouting at the school level. Where the results showed that as many as 29 states are needed for implementation in schools. As for most of that during this Law 63 successfully executed well by the coaches at the school, about 35 people express this condition.

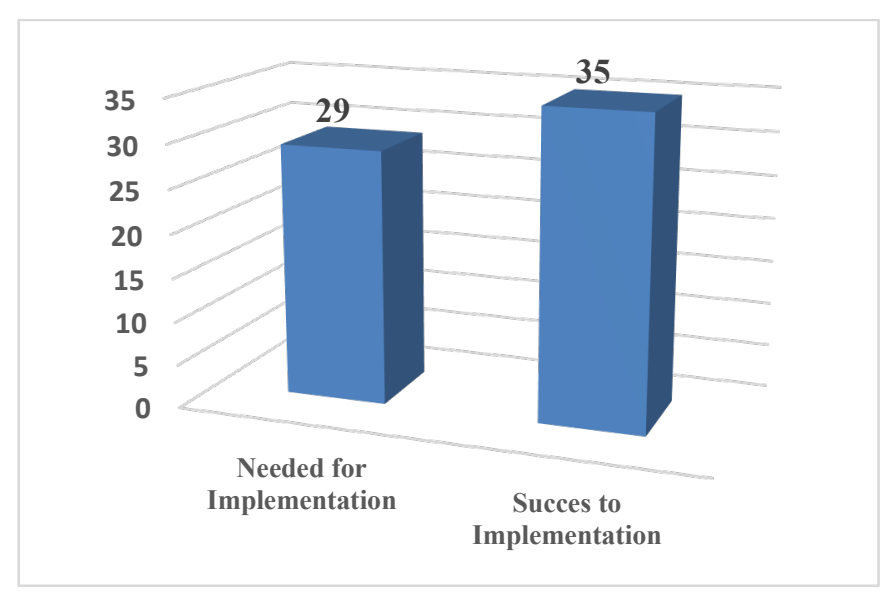

Figure 5: Data Measurement of Implementation The Government Role No.63 Year 2013 [17].

The success of the school in the Scout extracurricular programs, at least be able to promote the quality of service and guidance that has been done to other schools. This is, of course, will require education program marketing strategies appropriately. As a reference to the model of digital marketing through the website of the school in the education of which can be adopted on the findings of research conducted by Tripti Dhote, Yatin Jog, Nutan Gavade and Gesu Shrivastava (2015) [20] which states that "any form of direct or indirect marketing that is used to build awareness, recognition, recall, and action for a brand, business, product, person, or other entity and is carried out using the tools of the social Web, such as blogging, micro-blogging, social networking, social bookmarking, and content sharing". From those opinions, it can be recommended that the number of results and the strength of the Scout program should be packaged and disseminated through the online system of the school website. Thus, the success of the inter-school will rapidly grow together in an effort to instill the values of national identity through the Scout extracurricular program.

\section{Conclusions and Recommendations}

\subsection{Conclusion}

Implementation of the extracurricular field scouting program in the school can be done by providing socialization of the importance of such activities. Then set up a training program for prospective Pembina county level, district level and school level. Having formed the structure of Trustees of the management structure of the system is built coaches for the district, district and school. Once the structure and team coach this program, there was a dissemination of registration and membership training scouting. Every step is formulated in the extracurricular scouting program for this in Indonesia. There are a number of conditions that need to be considered in the implementation of this program, in particular, support for the program, Pembina power, infrastructure, financing. Meanwhile, to measure the success of this program required a clear law of the government, in Indonesia owned by Law No. 63 of 2014 [14] as an umbrella implementation scouting extracurricular activities at school. During this time the law provides enough ease and success as well as the convenience of the implementation of the extracurricular program.

\subsection{Recommendation}

The Scout activities can be maintained as an extracurricular program that is capable of forming the character of the nation as a knowledgeable society and independent. In an effort to maintain a program that has been successful, thus the government regulation No. 63 [14] of the Implementation Program Extracurricular must be maintained by the school, district, and county. This needs to be supported by the government, schools, people and concerned citizens in efforts to form a national character

\section{Conflict of Interest}

The authors declare no conflict of interest.

\section{Acknowledgment}

The authors gratefully acknowledge that this work has been supported by a grant from the Ministry of Education and Culture of Republic Indonesia.

\section{References}

[1] Muhamad, B., \& Saparahayuningsih, S, "An Attitude and Character Instructional Development Based on Curriculum 2013 in Elementary School" Creative Education, 07(02), 269-277, 2016. https://doi.org/10.4236/ce. 2016.72025

[2] Njikeh, K. D, "The Mentally Offset Human and the Society" Open Journal of Psychiatry, 06(02), 188-190, 2016. https://doi.org/10.4236/ojpsych. 2016.62022

[3] Regulation of the Minister of Education and Culture of the Republic of Indonesia Number 81A of 2013 concerning the Implementation of Curriculum, 2013, pp. 1-97.

[4] Zhang, J. "Analysis on Standardization and Individualization of Nation Wear" Art and Design Review, 06(02), 96-107, 2018. https://doi.org/10.4236/adr. 2018.62009

[5] Law of the Republic of Indonesia Number 12 of 2014 concerning the Scout Movement, 2010, pp. 1-23.

[6] Scout Research and Development Center, West Java Regional Kwartir, Research Results, 2011, pp.22.

[7] Law of the Republic of Indonesia Number 20 of 2003 concerning the National Education System, 2003, pp. 1-26.

[8] Law of the Republic of Indonesia Number 12 of 2010 concerning the Scout Movement, 2010, pp. 1-23

[9] Hill, T.A., 2005. Character First! Kimray Inc., http://www.charactercities.org/ downloads / publications / Whatischaracter.pdf. downloaded on August 11, 2011.

[10] Ekowarni, Endang. Development of Budi Pekerti's Noble Values as National Character, 2009.

[11] Suyatno, Scouting Education through Education Unit-Based Clusters, East Java Pusdiklatda, Surabaya, 2014. 
[12] Gall M, Borg W, Gall J. Educational research: An introduction. White Plains, NY: Longman, 1996.

[13] Sugiyono, Educational Research Methodology, 2007.

[14] Hong-Joong Cho, Jung-Ran Kim, Sang-Gu Kim, "Special Education Discourses on Freedom of Speech and Discriminatory Speech", Indian Journal of Science and Technology, 2015 Mar, 8 (S5), Doi no: 10.17485 / just / 2015 / v8iS5 / 80027.

[15] M. Alsharari Mufadhi Ratyan, A. Almadani Maen Mohammad, "Saudi Higher Education Reality and Prospects: Evaluating Careers' Dimensions of University Teaching, Scientific Research and Community Service Northern Border University as a Model", Indian Journal of Science and Technology, 2016 Jan, 9 (4), Doi no: 10.17485 / ijst / 2016 / v9i4 / 84984

[16] V. Murugananthan, BL Shiva Kumar, "An Adaptive Educational Data Mining Technique for Mining Educational Data Models in Elearning Systems", Indian Journal of Science and Technology, 2016 Jan, 9 (3), Doi no: 10.17485 / ijst / 2016 / v9i3 / 86392

[17] Decree of the National Conference on Scouting Movement Number 11 / Munas / 2013 concerning the Statutes and By-Laws of the Scouting Movement, 2013.

[18] Regulation of the Minister of Education and Culture of the Republic of Indonesia Number 63 the Year 2014 Regarding Scouting Education as a Compulsory Extra-Curricular Activity in Basic Education and Secondary Education, 2014, pp.1-4

[19] Decree of the National Kwartir Number 231 of 2007 concerning Guidelines for the Implementation of the Front Scout Movement, 2007.

[20] Tripti Dhote, Yatin Jog, Nutan Gavade, Gesu Shrivastava, "Effectiveness of Digital Marketing in Education: An Insight into Consumer Perceptions", Indian Journal of Science and Technology, 2015 Feb, 8 (S4), doi no: 10.17485 / ijst / 2015 / v8iS4 / 70300. 